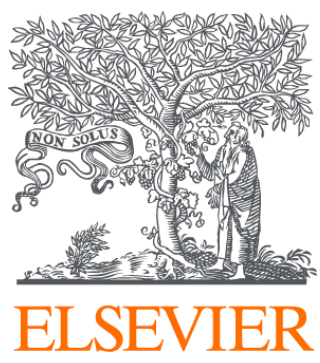

Since January 2020 Elsevier has created a COVID-19 resource centre with free information in English and Mandarin on the novel coronavirus COVID-

19. The COVID-19 resource centre is hosted on Elsevier Connect, the company's public news and information website.

Elsevier hereby grants permission to make all its COVID-19-related research that is available on the COVID-19 resource centre - including this research content - immediately available in PubMed Central and other publicly funded repositories, such as the WHO COVID database with rights for unrestricted research re-use and analyses in any form or by any means with acknowledgement of the original source. These permissions are granted for free by Elsevier for as long as the COVID-19 resource centre remains active. 


\title{
Epidemiology of Viral Respiratory Infections
}

\author{
Arnold S. Monto, MD
}

Acute respiratory tract infections are the most common illnesses in all individuals, regardless of age or gender. Epidemiologic surveys and communitybased studies conducted since the beginning of the 20th century have determined the rates of illness and the pathogens involved in such infections. These studies have shown that rhinoviruses cause the great majority of these respiratory illnesses, and their findings have examined the means of transmission of respiratory illness. More recently, advances in diagnostic techniques have enabled more complete identification of the viruses involved in respiratory infections, which has aided in the ability to direct specific therapeutic agents at the causative pathogens. $A m \mathrm{~J}$ Med. 2002;112(6A):4S-12S. (C) 2002 by Excerpta Medica, Inc.
From the Department of Epidemiology, School of Public Health, University of Michigan at Ann Arbor, Ann Arbor, Michigan, USA.

Requests for reprints should be addressed to Arnold S. Monto, MD, 109 Observatory Street, Ann Arbor, Michigan 48109.
A cute respiratory infections are the most common illnesses experienced by people of all ages worldwide. Data collected by the Health Interview Survey have demonstrated the overall scope of these illnesses. ${ }^{1}$ The Health Interview Survey defines acute conditions as those not lasting more than 3 months but requiring a physician consultation or restriction of daily activity. Only illnesses with onsets in the 2 weeks before the survey were reported. Table 1 shows the 1995 survey data on all acute conditions, categorized by age of the patient and, more specifically, by conditions involving the respiratory tract. Of all acute illnesses, respiratory conditions are the most common, generally occurring twice as frequently as the next most common condition. ${ }^{1}$

Within the category of respiratory conditions, influenza was reported more frequently than the common cold, despite the fact that colds occur more commonly. Illnesses were identified based simply by name, and not based on clinical characteristics. Furthermore, the specific questions varied over time. This is likely because of the fact that reporting in this survey was limited to more severe conditions (those involving a physician consultation or restricted activity), which are more apt to be recalled by the respondent. Therefore, in the Health Interview Survey the incidence of influenza is probably overestimated and that of the common cold underestimated. Although this survey may not represent the true incidence of these infections, the data do report all respiratory illnesses in the context of conditions requiring physician consultation. They support the finding that respiratory infections cause significant morbidity and are a major reason for physician visits and restricted activity.

\section{A HISTORIC OVERVIEW: FAMILY AND COMMUNITY STUDIES}

\section{Early Epidemiologic Studies}

Compared with the Health Interview Survey, a more accurate estimation of the frequency of viral respiratory infections (VRIs) in the US population is derived from long-term family and community studies. The data were gathered by means of regular contact with the households or individuals participating, in order to maximize illnesses reported and minimize recall bias. These studies began about 80 years ago and successfully documented the frequency of common respiratory illnesses, which are now recognized to be almost exclusively viral in cause. ${ }^{2}$

In studies reported during the 1920s and 1930s, observations were made that are supported by the findings of current epidemiologic studies. Very early studies showed 
Table 1. All Acute and Acute Respiratory Conditions Reported in the Health Interview Survey*

\begin{tabular}{lccccc}
\hline & \multicolumn{5}{c}{ Age Group (yr) } \\
\cline { 2 - 6 } & All Ages & $<5$ & $5-17$ & $18-24$ & $25-44$ \\
\hline All acute conditions ${ }^{\dagger}$ & 174 & 364 & 236 & 158 & 157 \\
All respiratory conditions & 85.2 & 159.5 & 122.8 & 79.7 & 80.5 \\
Common cold & 23.1 & 53.7 & 33.0 & 21.8 & 113 \\
Influenza & 41.2 & 53.6 & 59.4 & 43.1 & 50.5 \\
Other $^{*}$ & 20.9 & 52.2 & 30.4 & 14.8 & 14.6 \\
\hline
\end{tabular}

* Annual incidence per 100 persons.

${ }^{\dagger}$ Illness or injury lasting less than 3 months that caused a person to limit daily activity or contact a physician.

${ }^{*}$ Bronchitis, pneumonia, and other acute upper and lower respiratory conditions.

Adapted from Vital Health Stat. ${ }^{1}$

that children are at particular risk of developing VRIs, that the frequency of respiratory illnesses is higher among females, and that illnesses with coryza peak in autumn. ${ }^{3-5}$ At the time these observations were reported, the causative pathogens had not been identified. ${ }^{2}$

\section{The Cleveland Family Study}

In the late 1940s and 1950s there was an increased interest in respiratory illnesses, with research again concentrating on the influence of familial or household factors on incidence. $^{2}$ These studies were important because of the emerging ability to identify viruses as the causative agents.

The Cleveland family study was a seminal investigation conducted from 1948 to $1957 .{ }^{6}$ Its methods and observations provided a standard against which subsequent investigations were measured. ${ }^{2}$ This study serves as a bridge between the early studies that were carried out without any supporting virology and later studies in which laboratory data were an integral part of the investigation. When the study began in 1948, only influenza and "typical" bacteria could be identified. By 1953 adenovirus could also be identified. ${ }^{2}$ By the late 1950 s and early 1960 s it became possible to identify most viruses now known to be involved in respiratory illness, although the techniques have improved since, especially recently with the development of the polymerase chain reaction methodology. ${ }^{2}$ Furthermore, the longitudinal nature of the Cleveland family study allowed accumulation of sufficient numbers of observations to enable researchers to draw conclusions about subgroups and to take into account the year-toyear variation in the frequency and intensity of outbreaks. $^{2}$

The Cleveland study followed nearly 100 families in association with the Case Western Reserve Medical Center; it identified common respiratory illnesses and their cause to the extent possible at the time. ${ }^{6}$ Families were contacted weekly by visiting nurses. The occurrence of VRIs was determined by home visits in which illness symptoms were recorded and by obtaining blood speci- mens for serological testing in an attempt to identify the organism involved.

The cohabitating family unit was the focus of the study. ${ }^{6}$ The important contribution of the research was the reliable and accurate data obtained on the frequency of respiratory illnesses in the family setting and the importance of the family setting in transmission. The data obtained were probably the most accurate in terms of the annual frequency of respiratory infections. ${ }^{6}$ Table 2 shows the number of respiratory illnesses reported, categorized by age. ${ }^{6}$ The highest numbers of illnesses were in young children (up to 4 years of age); illnesses decreased with increasing age. The importance of young children has undoubtedly increased in recent years with the dramatic increase in day care, but the exact effect is hard to quantify because of the lack of comprehensive studies from which incidence can be determined. Although this study was relatively small, there was a concentrated effort to report information carefully so that the numbers were the most accurate as determined in a US population.

The investigators found that there was an increased risk of developing an illness if another family member

Table 2. Annual Frequency of Respiratory Illness by Age: Cleveland Family Study, 1948-1957*

\begin{tabular}{lc}
\hline Age $($ yr $)$ & $\begin{array}{c}\text { Common } \\
\text { Respiratory Disease }\end{array}$ \\
\hline$<1$ & 6.72 \\
$1-4^{\dagger}$ & 7.95 \\
$5-9^{\dagger}$ & 6.21 \\
$10-14^{\dagger}$ & 5.02 \\
$15-19^{\dagger}$ & 4.71 \\
$20-24$ & 4.09 \\
$25-29$ & 4.82 \\
$30-34$ & 4.45 \\
$35-39$ & 3.83 \\
$40-44$ & 3.68 \\
$45-49$ & 3.97 \\
\hline
\end{tabular}

${ }^{*}$ Adapted from $\mathrm{Am} \mathrm{J} \mathrm{Hyg}{ }^{6}$ and Epidemiol Rev. ${ }^{2}$

${ }^{\dagger}$ Unweighted means of individual ages. 
Table 3. Mean Annual Incidence of Total Respiratory Illness per Person-Year (Tecumseh, Michigan, 1966-1971*)

\begin{tabular}{lcccc}
\hline & \multicolumn{4}{c}{ Mean Annual Illness Incidence } \\
\cline { 2 - 5 } $\begin{array}{l}\text { Age Group } \\
\text { (yr) }\end{array}$ & $\begin{array}{c}\text { Person-Years } \\
(\mathrm{n}=4,905)\end{array}$ & Males & Females & Both Sexes \\
\hline$<1$ & 121 & 6.3 & 6.0 & 6.1 \\
$1-2$ & 302 & 6.0 & 5.4 & 5.7 \\
$3-4$ & 284 & 4.4 & 5.1 & 4.7 \\
$5-9$ & 844 & 3.4 & 3.7 & 3.5 \\
$10-14$ & 720 & 2.4 & 3.1 & 2.7 \\
$15-19$ & 318 & 2.1 & 2.8 & 2.4 \\
$20-24$ & 234 & 2.2 & 3.3 & 2.8 \\
$25-29$ & 397 & 2.4 & 3.1 & 2.7 \\
$30-39$ & 897 & 1.9 & 2.7 & 2.3 \\
$40-49$ & 502 & 1.4 & 1.9 & 1.7 \\
$50-59$ & 125 & 1.3 & 1.8 & 1.6 \\
$\geq 60$ & 161 & 0.9 & 1.4 & 1.3 \\
\hline
\end{tabular}

* Adapted from JAMA. $^{7}$

Mean Annual IIIness Incidence

(\%)

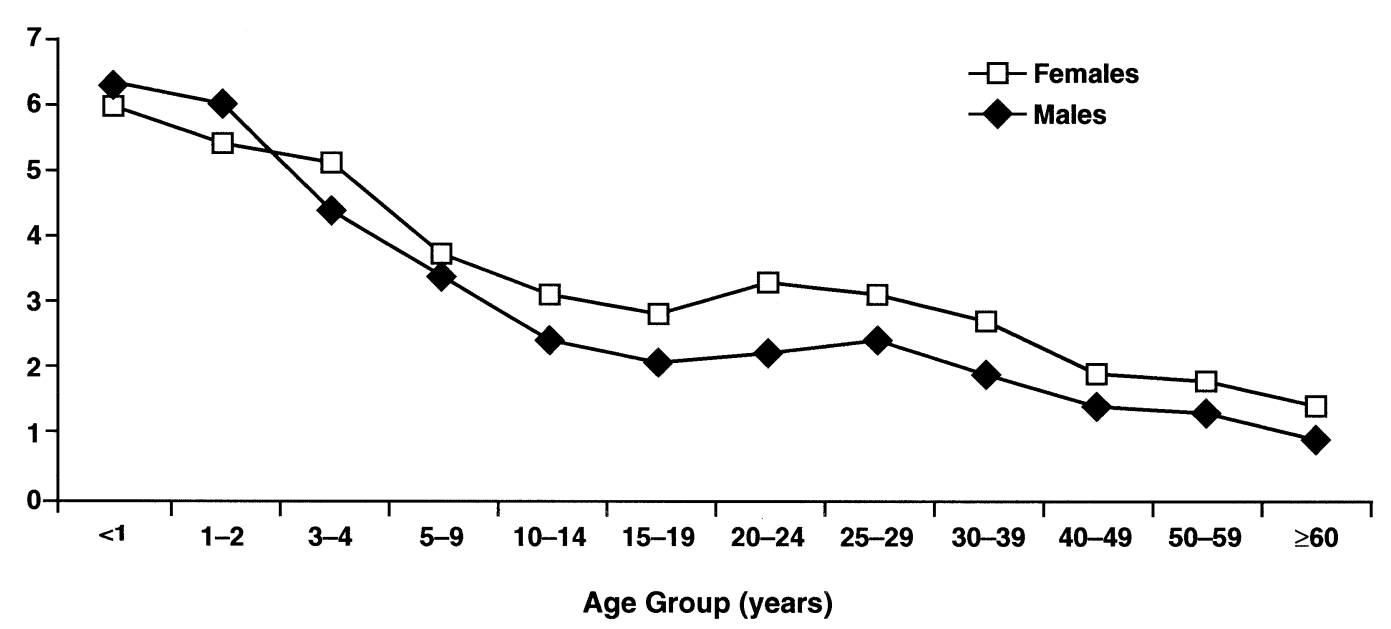

Figure 1. Mean annual incidence of total respiratory illness per person-year, Tecumseh, Michigan, 1966-1971. (Adapted from JAMA. ${ }^{7}$ )

was sick. ${ }^{6}$ In the family setting, it was found that the most likely introducers of infection were children in various age categories, particularly children in preschool; mothers were the next most common introducers. Fathers were the least likely introducers of illness into the family.

\section{The Tecumseh, Michigan, Studies}

More recent investigations have continued to focus on the family, with the added ability to identify the causal agents. In the Tecumseh, Michigan, study, approximately 1,000 individuals living in a community were followed in 2 phases. $^{7,8}$ The studies of acute infection began in 1965 and continued through 1971, phase 1. The second part began again in 1976 and concluded in 1981.

Data were collected using weekly questionnaires to identify illness onset, specimen collection for agent isolation from participants with illness, and regular blood col- lection for serologic identification of infection. ${ }^{2}$ Simple reporting of an illness without specific required symptoms was insufficient for an episode to be recognized as an acute respiratory illness. The mean annual incidence of total respiratory infections (mostly viral) is shown in Table 3. Because of the number of subjects followed, it was also possible to examine the difference in incidence between males and females (Figure 1). ${ }^{7}$

Illnesses were more frequent in young boys than in girls up to 3 years of age, at which point the incidence became more frequent in females. At age 5 to 9 years, the frequency of respiratory illnesses in general began to decrease. The increase in frequency at age 20 to 29 years might be explained by exposure of family members to young children with respiratory infections. The increase occurred to a greater extent in females. 
Table 4. Relation of Family Income to Annual Incidence of Respiratory Illness

\begin{tabular}{lrcc}
\hline & & \multicolumn{2}{c}{$\begin{array}{c}\text { Mean Annual No. of } \\
\text { Respiratory Illnesses per } \\
\text { Person }\end{array}$} \\
\cline { 3 - 4 } $\begin{array}{l}\text { Income Range } \\
\text { US \$) }\end{array}$ & $\begin{array}{c}\text { No. in } \\
\text { Group }\end{array}$ & Unadjusted & Age-Adjusted \\
\hline$<5,000$ & 185 & 3.8 & 3.8 \\
$5,000-6,999$ & 603 & 3.4 & 3.1 \\
$7,000-9,999$ & 1,504 & 3.2 & 3.0 \\
$10,000-14,999$ & 969 & 2.8 & 2.9 \\
$>15,000$ & 371 & 2.7 & 3.0 \\
\hline
\end{tabular}

* Income data from 1974 .

Adapted from JAMA. ${ }^{7}$

Table 5. Relation of Number Sharing Bedroom to Individual Conversion Rates for the 3 Most Common Rhinoviruses

\begin{tabular}{lccc}
\hline & \multicolumn{3}{c}{$\begin{array}{c}\text { No. of Conversions per } \\
\text { Antibody-Deficient Individuals }\end{array}$} \\
\cline { 2 - 4 } & & $\%$ & $\begin{array}{c}\text { Individuals } \\
\text { Studied (n) }\end{array}$ \\
\hline 1 & $(\mathrm{n})$ & 30.0 & 24 \\
2 & $12 / 40$ & 41.3 & 120 \\
3 & $52 / 126$ & 58.9 & 58 \\
4 & $53 / 90$ & 44.0 & 48 \\
5 & $37 / 84$ & 59.2 & 37 \\
6 & $45 / 76$ & 48.1 & 17 \\
7 & $13 / 27$ & 68.4 & 10 \\
8 & $13 / 19$ & 68.8 & 33 \\
No information & $44 / 64$ & 62.5 & 7
\end{tabular}

Adapted from Am J Epidemiol. ${ }^{9}$

$\chi_{1}^{2}=18.1$

$P<0.0001$.

Further analysis of data from the study ${ }^{8}$ showed that women who did not work outside the home had higher rates of respiratory illness than women who worked out of the home. Among women working out of the home, however, the frequency of illness was still greater than that experienced by males. These data seemed to confirm that exposure to the children in the family increased the likelihood of respiratory illnesses.

Additional analysis of infection occurrences shows an inverse relationship between income and frequency of respiratory illness (Table 4). ${ }^{7}$ This is probably a reflection of greater household crowding. This relationship has been directly demonstrated for rhinovirus infection by studies reporting the relationship between the number of individuals sharing a bedroom and seroconversion rates for the 3 most common rhinovirus serotypes (Table 5). ${ }^{9}$ Illness frequency increased with crowding of sleeping conditions.

Illness incidence also varied by day of infection onset (Figure 2). ${ }^{9}$ Data were collected on the day of illness onset so the researchers could calculate secondary attack rates and determine family transmission. In the school-age children, illnesses were less frequent in the middle of the week. Assuming an incubation period of 2 to 4 days, school transmission could explain this kind of pattern, which is most pronounced in individuals 5 to 19 years old.

\section{CAUSE OF VIRAL RESPIRATORY INFECTIONS}

Community-based studies have made it possible to determine the cause of common VRIs. Further specific causes have been determined by specially designed studies. In the Tecumseh study, the viruses causing all respiratory infections were reported. The distribution of pathogens was determined by self-reported illness, whether it was a specific syndrome (ie, influenza) or an illness with only 1 symptom. In the Tecumseh study, rhinoviruses were by far the most frequent viral isolate identified in the overall population (Figure 3 ). ${ }^{10}$

In the first phase of the study, an infectious agent was detected in only approximately $25 \%$ of the specimens collected. ${ }^{2}$ Not all specimens collected yielded virus isolates, partly because advanced diagnostic techniques, such as polymerase chain reaction (PCR), were not available at the time the study was conducted.

Table 6 shows the annual isolation rates of various respiratory viruses by age (actual rates per 1,000 personyears) during the second phase of the study, from 1976 to 1981. Rates per 100 person-years were adjusted by the proportion of illnesses actually sampled. ${ }^{8}$ The adjustments approximate isolation rates as if all infections had been sampled. Both rates were based on actual isolation of virus. Nonculturable viruses, or those lost during shipping from the site to the laboratory, were not included. Again, in this second phase, rhinoviruses were the most frequently isolated agents in all age groups.

Table 7 shows the relative role or impact of various respiratory viruses in producing acute respiratory infections. ${ }^{8}$ In this table, estimates were made of the degree to which virus-isolation techniques underestimated the actual role of each agent in infection, and an appropriate adjustment was made. (As mentioned, PCR techniques did not exist at the time this study was conducted.) Rhinovirus rates were adjusted based on a study of the common cold in which previous organ culture technique identified viruses that did not replicate in ordinary cell culture. Based on these studies, rhinoviruses were still the most common isolate. Of note is the large percentage of illnesses for which the cause could not be determined. Also, although rhinoviruses caused a less severe illness syndrome than some of the other pathogens, especially influenza, owing to its high frequency rhinovirus infection resulted in more physician consultations in the United States than any other single agent. 

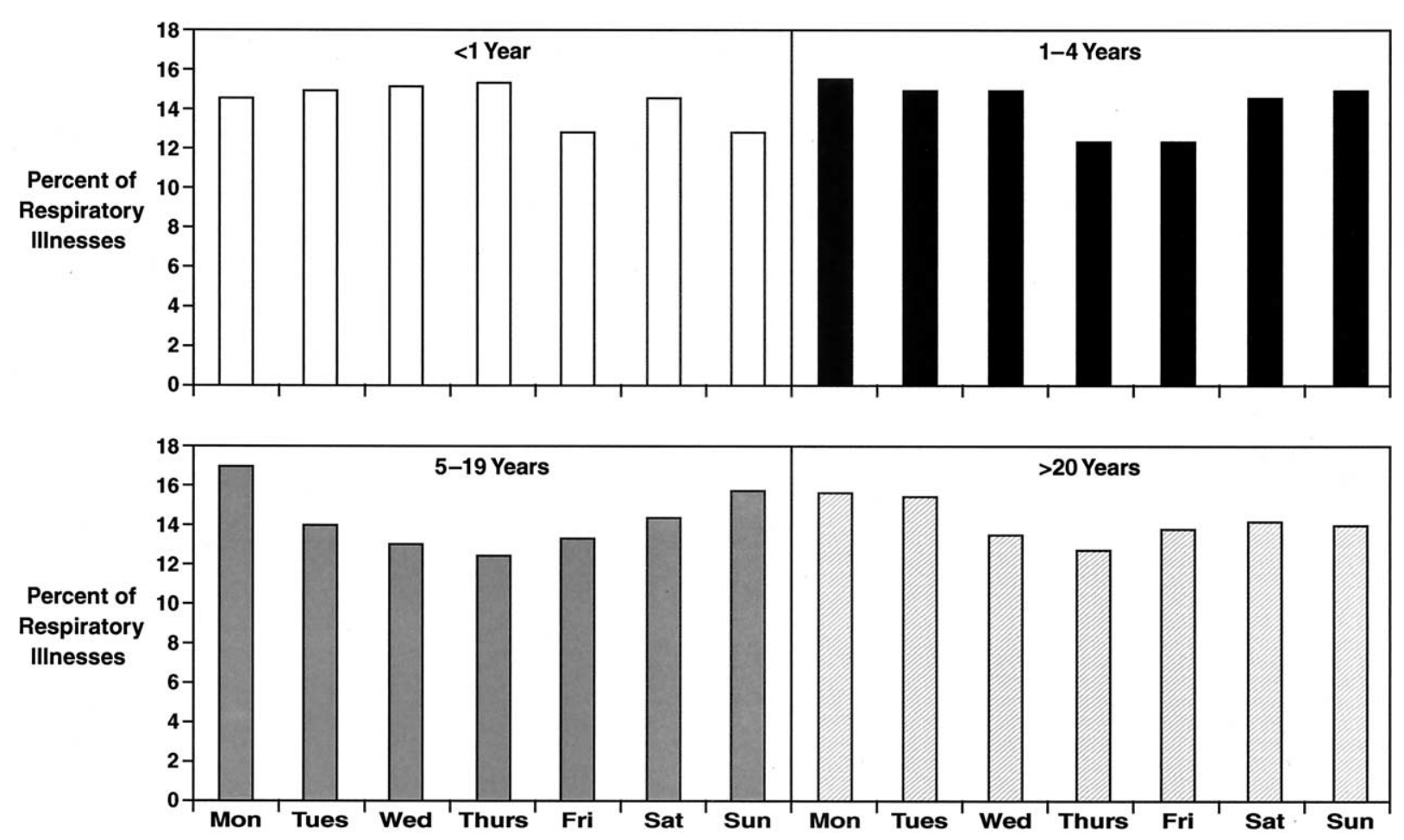

Figure 2. Proportion of respiratory illnesses that began on each day of the week. (Adapted from Am J Epidemiol. ${ }^{9}$ )

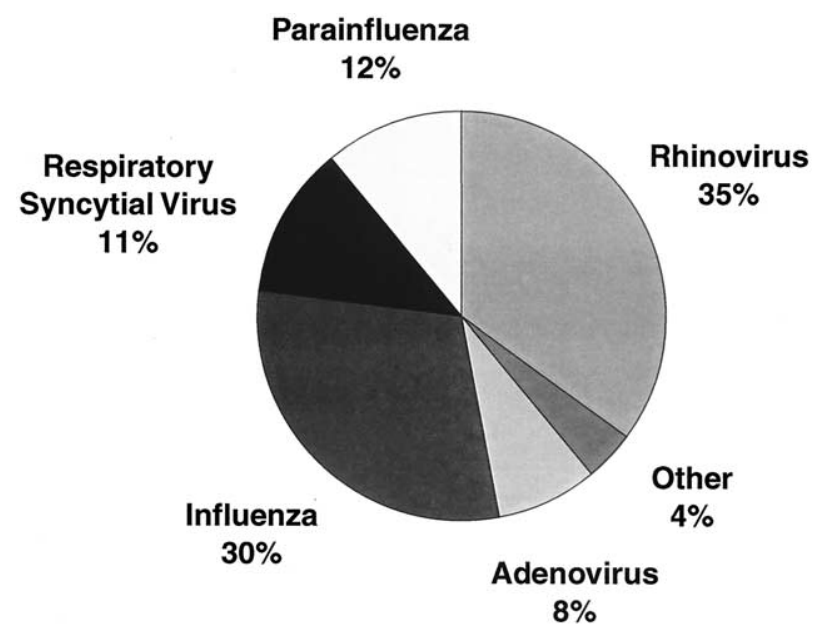

Figure 3. Percentage distribution of isolates of virus in the surveillance population in Tecumseh, Michigan, 1966-1981. (Adapted from J Infect Dis. ${ }^{13}$ )

\section{SEASONALITY OF RESPIRATORY INFECTION IDENTIFIED IN EPIDEMIOLOGIC STUDIES}

Virus isolation is valuable in determining seasonality of the pathogens causing respiratory infection. ${ }^{2}$ Seasonality is one of the characteristics of respiratory viruses that has been identified in epidemiologic studies, but the reasons for this seasonality are unclear. Although clinical signs and symptoms of various VRIs can overlap, it is possible to determine the probability of illnesses being caused by a specific virus based on the syndrome produced and on the differing seasonalities of those viruses.

As shown in Figure 4, respiratory syncytial virus and influenza virus occur mainly in the winter to early spring. ${ }^{11}$ Although they occur in most months, parainfluenza viruses predominate in the late autumn into the winter. Rhinoviruses cause VRIs in all months of the year, with peaks of illness in the fall (the major peak) and in the 
Table 6. Annual Isolation Rates of Respiratory Viruses, Tecumseh, Michigan, 1976-1981: Actual Rates per 1,000 Person-Years, and Rates per 100 Person-Years Adjusted by Proportion of Illnesses Sampled (in parentheses)

\begin{tabular}{|c|c|c|c|c|}
\hline \multirow[b]{2}{*}{ Agent } & \multicolumn{4}{|c|}{ Age Group (yr) } \\
\hline & $0-4(539)^{\star}$ & $5-19(1,541)^{*}$ & $20-39(1,523)^{\star}$ & $40+(1,757)^{\star}$ \\
\hline Rhinoviruses & $113.2(59.6)^{\dagger}$ & $25.3(13.2)$ & $38.7(21.5)$ & $9.7(8.8)$ \\
\hline Influenza A (H3N2) & $16.7(8.8)$ & $10.4(5.5)$ & $5.9(3.3)$ & $6.8(6.2)$ \\
\hline Influenza A (H1N1) & $7.4(3.9)$ & $26.6(14.0)$ & $2.0(1.1)$ & $0.0(0)$ \\
\hline Influenza type B & $3.7(1.9)$ & $20.8(10.9)$ & $7.2(4.0)$ & $3.4(3.1)$ \\
\hline Parainfluenza viruses & $53.8(28.3)$ & $14.3(7.5)$ & $3.9(2.2)$ & $2.3(2.1)$ \\
\hline Respiratory syncytial viruses & $55.7(29.3)$ & $7.1(3.7)$ & $6.6(3.7)$ & $2.3(2.1)$ \\
\hline Adenoviruses & $33.4(16.6)$ & $6.4(3.4)$ & $4.6(2.6)$ & $1.1(1.0)$ \\
\hline Other & $9.2(4.8)$ & $5.2(2.7)$ & $2.0(1.1)$ & $1.1(1.0)$ \\
\hline Total & $293.1(154.3)$ & $116.1(61.1)$ & $70.9(39.4)$ & $26.7(24.3)$ \\
\hline
\end{tabular}

* Number of person-years of observation.

${ }^{\dagger}$ Actual isolation rates per 1,000 (adjusted isolation rates per 100).

Reprinted with permission from Epidemiol Infect. ${ }^{8}$

Table 7. Estimated Percentage of All Respiratory Illnesses Caused by Specific Etiologic Agents: Percentage of Such Illnesses with Physician Consultation and Annual Numbers of Each in the Population $(\mathrm{N}=10,000)$ of Tecumseh, Michigan

\begin{tabular}{lcccr}
\hline Etiologic Agent & $\begin{array}{c}\text { Percentage of } \\
\text { All Illnesses }\end{array}$ & $\begin{array}{c}\text { Illnesses per 10,000 } \\
\text { Population (n) }\end{array}$ & $\begin{array}{c}\text { Illnesses with } \\
\text { Consultation (\%) }\end{array}$ & $\begin{array}{r}\text { Illnesses with Consultation } \\
\text { per 10,000 Population (n) }\end{array}$ \\
\hline Rhinoviruses & 34 & 8,325 & 17.6 & 1,465 \\
Coronaviruses & 14 & 3,428 & 17.6 & 603 \\
Influenza & 9 & 2,204 & 37.9 & 835 \\
Bacterial & 8 & 1,959 & 48.6 & 952 \\
Parainfluenza viruses & 4 & 979 & 26.2 & 257 \\
Respiratory syncytial viruses & 4 & 979 & 55.6 & 544 \\
Adenoviruses & 2 & 490 & 43.2 & 212 \\
Other viruses & 2 & 490 & 27.8 & 136 \\
Unknown and/or noninfectious & 23 & 5,630 & 21.5 & 1,211 \\
Total & 100 & 24,484 & 25.4 & 6,215 \\
\hline
\end{tabular}

Adapted from Epidemiol Infect. ${ }^{8}$

spring, as shown in Figure 5. ${ }^{12}$ The rhinovirus outbreaks in the fall are a result of children returning to school. These seasonality data were confirmed in studies that used interferon-alpha for seasonal prophylaxis against rhinovirus infection in a university student population. ${ }^{13}$ The small peak in the spring has a variable pattern because of the size of the United States and differing seasonal weather patterns nationwide. ${ }^{2}$

Worldwide, the seasonality of rhinoviruses and other respiratory agents varies geographically, according to temperate versus cold and/or rainy climates. ${ }^{14}$ Whereas it is difficult to determine, based on current data, how climate affects the known occurrence of rhinovirus in temperate areas, such data are available for influenza, which is most prevalent in the rainy season in those areas with little temperature fluctuation. Nonetheless, it has been shown that rhinoviruses are the most common cause of viral respiratory disease globally. This is particularly true in the developing world, where crowding results in higher transmission and illness frequency early in life.

\section{TRANSMISSION OF RHINOVIRUS INFECTION}

The pathogens that cause viral respiratory disease vary in their ability to initiate and transmit infection. The mode of transmission of rhinovirus has been widely debated over the years. ${ }^{2}$ Experimental studies of natural transmission of rhinovirus to determine routes and probability of transmission are rarely feasible and often cannot approximate natural transmission. Therefore, conclusions are typically drawn from epidemiologic observations.

For example, influenza can transmit easily by airborne spread, that is, by aerosol as well as by large droplet. ${ }^{15}$ Colds were believed to be transmitted by large droplet only. However, it was shown experimentally that rhinovirus infection could be produced by inoculating contaminated secretions from infected individuals into the noses or eyes of volunteers. ${ }^{15}$ The question remained as to whether rhinovirus is transmitted primarily by direct contact, that is, by droplet nuclei or by indirect contact. The transmission issue is still controversial. 

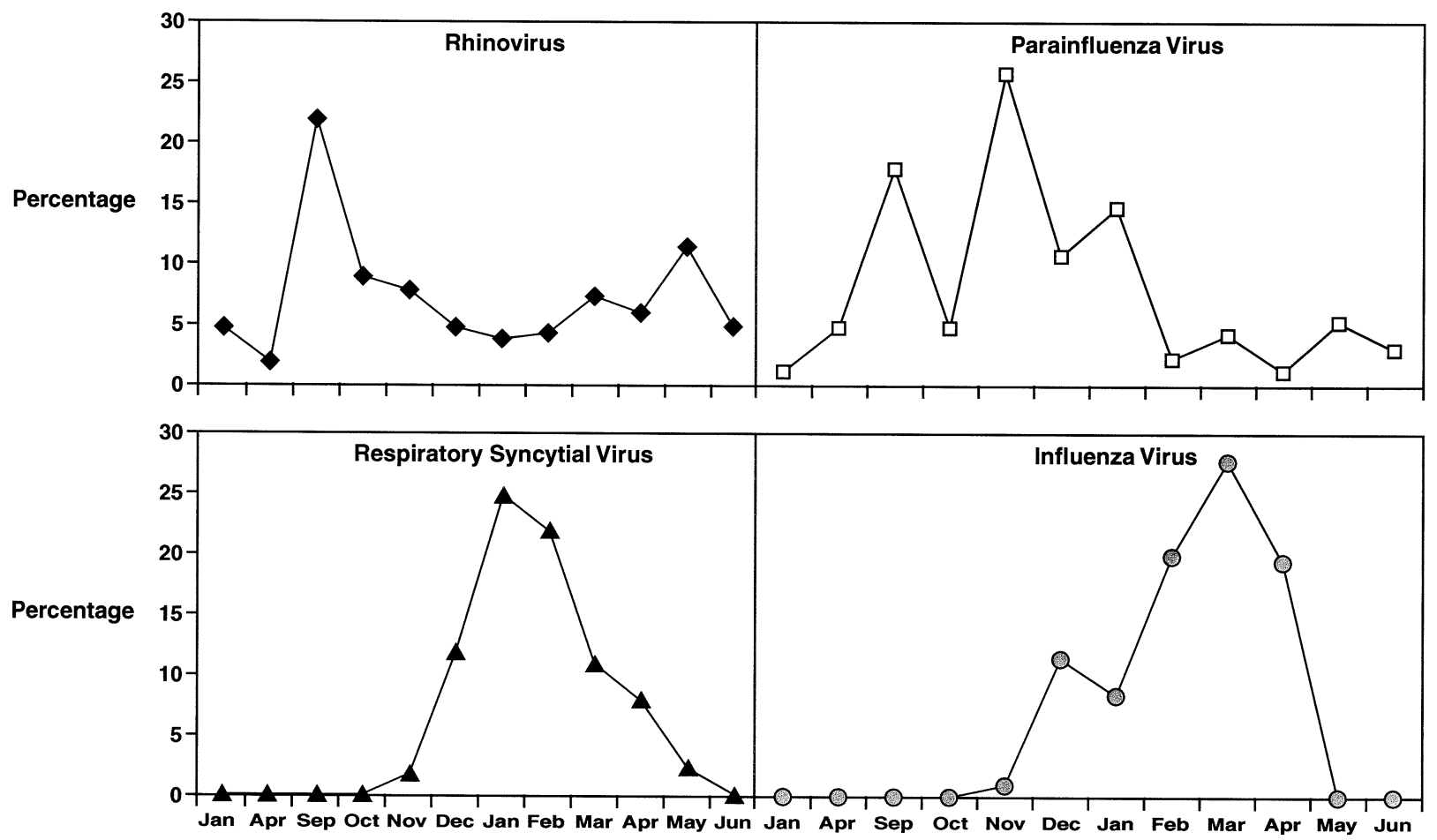

Figure 4. Acute respiratory illness in the community, seasonality of respiratory agents: proportion isolated in each calendar month during study years. (Adapted from Am J Epidemiol. ${ }^{11}$ )

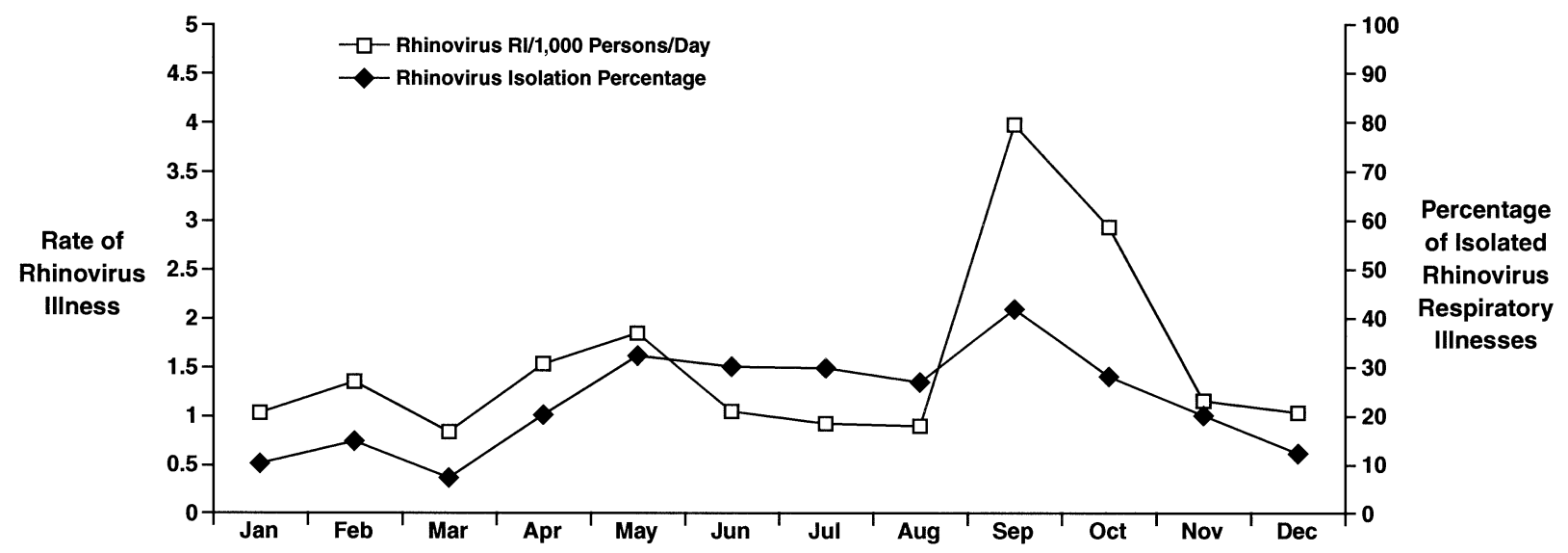

Figure 5. Combined data for the 3-year period, March 1963 to March 1966, depicting the seasonal variation in the percentage of sampled respiratory illnesses yielding rhinoviruses and, in the rate of rhinovirus illness, derived by application of this percentage to the total rate of respiratory illness. (Adapted from $\mathrm{N}$ Engl J Med. ${ }^{12}$ )

Gwaltney and Hendley ${ }^{16}$ showed that rhinoviruses could survive on surfaces and that rhinoviruses could be transmitted by finger-to-nose inoculation. This group from the University of Virginia at Charlottesville considered that contact with infected secretions is the principal mode of transmission. They found that volunteers in contact with contaminated objects or with the fingers of individuals with rhinovirus colds had a high rate of infection if they inoculated their own noses or eyes. Further- more, the investigators discovered that transmission could be interrupted by treating surfaces of contaminated objects with disinfectant or by applying iodine to the fingers. They found little evidence of transmission by means of droplets. ${ }^{17}$

In contrast, Dick et al, ${ }^{18}$ from the University of Wisconsin, showed that this mechanism is not required for rhinovirus transmission, and they found evidence that rhinovirus could be spread by droplet transmission. 
Those studies were carried out with volunteers, one of whom was inoculated with virus. Others were known to be susceptible to the virus and were exposed to the infected individuals under different circumstances. In the final experiment, the volunteers played cards with each other. One was experimentally infected, and all wore collars preventing their putting hands in their noses or eyes. Transmission still took place.

In summary, whereas some experts agree that indirect contact with contaminated secretions appears to be the most efficient means of transmission, ${ }^{19}$ others find that large-droplet transmission of such secretions is more important. ${ }^{15}$ Both routes undoubtedly operate under natural conditions. It is probably futile to hope that hand disinfection alone will result in interruption of transmission. There are thus sufficient data to suggest that close exposure to a person with infection, especially in the family setting, is required and is a major risk factor for acquiring rhinovirus infection. This finding is further supported by data indicating that crowding in the home facilitates transmission. $^{7}$

\section{THE EPIDEMIOLOGIC SIGNIFICANCE OF RHINOVIRUS SEROTYPES}

The large number of rhinovirus serotypes (over 100) has been a challenge, both in terms of laboratory procedures and reagents required for identification and in the development of a vaccine or antiviral medication to combat rhinovirus. The finding of a multiplicity of serotypes allowed demonstration of the fact that the seasonal outbreaks were actually a summation of mini-outbreaks, in which a large number of serotypes spread in a similar fashion. It also allowed demonstration that even in the same family, more than 1 serotype can be circulating, which indicates multiple introductions. ${ }^{9,10,20}$

The number of serotypes became critical, because vaccine prevention initially appeared to be the ideal way to prevent rhinovirus infections. However, there were 2 related questions to address in vaccine development. The first question was whether the number of serotypes was fixed or whether, like influenza, new serotypes were continuing to evolve. It gradually emerged that the number of serotypes is fixed. ${ }^{10,21}$

The second question related to whether there was a difference in the relative activity of various rhinovirus serotypes and whether certain rhinoviruses transmit more easily than others. This was initially based on recognition of certain types as more "common" causes of respiratory infections while others are rarely seen. ${ }^{2,9,20}$ These common serotypes would be a priority for vaccine development.

The hypothesis of common serotypes causing respiratory infections was confirmed by several studies. ${ }^{10,22,23}$ It was finally determined, however, that although common serotypes existed, those that were common changed over time. ${ }^{2,10}$ Because of this fact and similar findings, the development of specific antiviral agents appeared to offer more promise than vaccine development for control of VRIs resulting from rhinovirus.

\section{RECENT DEVELOPMENTS HELP TO CONFIRM THE EPIDEMIOLOGY OF RHINOVIRUS}

Isolation rates of viruses have varied from early studies to the more recent studies as diagnostic testing has become more sophisticated. The development of PCR has allowed identification of rhinoviruses and confirmation of the proportion of respiratory infections caused by the rhinoviruses. PCR has been shown to be more sensitive and often more rapid than culture isolation of respiratory viruses. ${ }^{24}$

Another reason for the differences in picornavirus isolation rates between epidemiologic studies is at least in part related to the case definitions used and timing of the studies (eg, length of study and season in which it is conducted). Self-diagnosed illnesses in which only 1 respiratory symptom was required (as in the Tecumseh studies) yield fewer isolates than sampling illnesses in which more symptoms are required.

For example, in Finland, a study in 200 young adults with self-diagnosed colds and clinical evidence of symptoms (rhinorrhea, nasal congestion, and sore throat confirmed by the physician) was conducted over a 10-month period. ${ }^{25}$ In total, a viral cause was found in $69 \%$ of cases. The rhinovirus isolation rate was $40 \%$. An additional $12 \%$ of rhinovirus-positive samples were detected by PCR, with a total rhinovirus identification rate of $52 \%$.

A Virginia study of young adults with self-diagnosed colds confirmed that PCR increases the rate of picornavirus detection. ${ }^{26}$ This study was conducted over a 2 -month period during the autumn peak of illness. The isolation rate of rhinoviruses (and a few other picornaviruses) using culture was $67 \%$. With the addition of PCR, the total picornavirus identification rate increased to $82 \%$.

\section{CONCLUSIONS}

Early epidemiologic studies documenting that children are at particular risk for VRIs have stood the test of time, as have other findings, such as a higher frequency of illnesses in females and autumn and spring peaks of illness. Rhinoviruses are by far the most frequent viral isolate identified in persons with colds. They cause VRIs in all months of the year, but major peaks occur in the fall and in the spring; the fall peak follows the opening of schools. The mechanism of transmission of rhinovirus remains unclear, and the significance of indirect transmission is still under debate. PCR techniques have been able to identify more completely rhinoviruses in studies of per- 


\section{A Symposium: Epidemiology of Viral Respiratory Infections/Monto}

sons with suspected VRIs. However, they have not been used in population-based studies, so the actual role of these agents in important syndromes can only be inferred. A particular need for future work is to determine the seasonality of rhinoviruses in areas without a clear winter season and the role of symptoms in predicting which infections are likely caused by rhinovirus. Such determinations will be of value in identifying which patients with respiratory illnesses should be treated when antirhinovirus drugs are available.

\section{References}

1. Benson V, Marano MA. Current estimates from the National Health Interview Survey 1995. Vital Health Stat. 1998;10:1428.

2. Monto AS. Studies of the community and family: acute respiratory illness and infection. Epidemiol Rev. 1994;16: 351-373.

3. Sydenstricker E. A study of illness in a general population group. Hagerstown Morbidity Studies no. I: The method and general results. Public Health Rep. 1926;41:20692088.

4. Frost $\mathrm{WH}$, Gover $\mathrm{M}$. The incidence and time distribution of common colds in several groups kept under continuous observation. Public Health Rep. 1932;47:1815-1841.

5. Van Volkenburgh VA, Frost WH. Acute minor respiratory diseases prevailing in a group of families residing in Baltimore, Maryland, 1928-1930: prevalence, distribution and clinical description of observed cases. Am J Hyg. 1933;17: 122-153.

6. Badger GF, Dingle JH, Feller AE, Hodges RG, Jordan WS $\mathrm{Jr}$, Rammelkamp $\mathrm{CH}$ Jr. A study of illness in a group of Cleveland families. II. Incidence of common respiratory disease. Am J Hyg. 1953;58:31-40.

7. Monto AS, Ullman BM. Acute respiratory illness in an American community. JAMA. 1974;227:164-169.

8. Monto AS, Sullivan KM. Acute respiratory illness in the community: frequency of illness and the agents involved. Epidemiol Infect. 1993;110:145-160.

9. Monto AS. A community study of respiratory infections in the tropics. III. Introduction and transmission of infections within families. Am J Epidemiol. 1968;88:69-79.

10. Monto AS, Bryan ER, Ohmit S. Rhinovirus infections in Tecumseh, Michigan: frequency of illness and numbers of serotypes. J Infect Dis. 1987;156:43-49.

11. Monto AS, Cavallaro JJ. The Tecumseh study of respiratory illness. II. Patterns of occurrence of infection with respiratory pathogens, 1965-1969. Am J Epidemiol. 1971;94:280289.

12. Gwaltney JM Jr, Hendley JO, Simon G, Jordan WS Jr. Rhinovirus infections in an industrial population. I. The occurrence of illness. N Engl J Med. 1966;275:1261-1268.

13. Monto AS, Shope TC, Schwartz SA, Albrecht JK. Intranasal interferon-alpha $2 b$ for seasonal prophylaxis of respiratory infection. J Infect Dis. 1986;154:128-133.

14. Gwaltney JM. Rhinovirus. In: Mandell GL, Bennett JE, Dolin $\mathrm{R}$, eds. Principles and Practice of Infectious Diseases, 4th ed. New York: Churchill Livingstone, 1995:1656-1663.

15. Goldmann DA. Transmission of viral respiratory infections in the home. Pediatr Infect Dis J. 2000;19(10 suppl):S97S102.

16. Gwaltney JM Jr, Hendley JO. Rhinovirus transmission: one if by air, two if by hand. Am J Epidemiol. 1978;107:357361.

17. Hendley JO, Gwaltney JM Jr. Mechanisms of transmission of rhinovirus infections. Epidemiol Rev. 1988;10:242-258.

18. Dick EC, Jennings LC, Mink KA, Wartgow CD, Inhorn SL. Aerosol transmission of rhinovirus colds. J Infect Dis. 1987; 156:442-448.

19. Turner RB. The common cold. Pediatr Ann. 1998;27:790795.

20. Monto AS, Johnson KM. A community study of respiratory infections in the tropics. I. Description of the community and observations on the activity of certain respiratory agents. Am J Epidemiol. 1967;86:78-92.

21. Calhoun AM, Jordan WS Jr, Gwaltney JM Jr. Rhinovirus infections in an industrial population. V. Change in distribution of serotypes. Am J Epidemiol. 1974;99:58-64.

22. Monto AS. The Tecumseh Study of Respiratory Illness. V. Patterns of infection with the parainfluenza viruses. Am J Epidemiol. 1973;97:338-348.

23. Fox JP, Cooney MK, Hall CE, Foy HM. Rhinoviruses in Seattle families, 1975-1979. Am J Epidemiol. 1985;122: 830-846.

24. Steininger C, Aberle SW, Popow-Kraupp T. Early detection of acute rhinovirus infections by rapid reverse transcriptionPCR assay. J Clin Microbiol. 2001;39:129-133.

25. Makela MJ, Puhakka T, Ruuskanen O, et al. Viruses and bacteria in the etiology of the common cold. $J$ Clin Microbiol. 1998;36:539-542.

26. Arruda E, Pitkäranta A, Witek TJ, Doyle CA, Hayden FG. Frequency and natural history of rhinovirus infections in adults during autumn. J Clin Microbiol. 1997;35:28642868. 